\title{
Conceptual Design and Validation of Meta-Model for Active e-Learning
}

\author{
Lilia Cheniti Belcadhi and Sonia Ayachi Ghannouchi
}

\begin{abstract}
Active Learning improves student attitudes and develops thinking and writing skills. It is increasingly recommended as a teaching method to improve learning. In this paper we are interested in the transformation of a face to face active course into a web-based active course. First we propose a mapping between concepts related to active instructional methods and corresponding online concepts. Further to this mapping exercise, a meta-model, including pedagogical and technical concepts, is designed. In order to evaluate and validate the proposed mapping and meta-model a case study is carried out. It concerns the transformation of an entrepreneurship active course into an online version and its deployment in the context of a training of trainers.
\end{abstract}

Index Terms-Active learning, active e-learning, meta-model, mapping, instructional design.

\section{INTRODUCTION}

Active Learning improves student attitudes and develops thinking and writing skills. It is increasingly recommended as a teaching method to improve learning. Active learners strive to take greater responsibility for their own learning by taking a dynamic role in deciding how and what they need to know, what they should be able to do, and how they are going to do it [1]. Examples of active learning methods include collaborative learning, problem-based learning, case studies, projects, simulations, and technology uses. These methods encourage student engagement with critical thinking, analysis, synthesis, and evaluation of information. Moreover, during the last few years, e-learning has been promoted in various disciplines and constituted a new way of giving courses in many universities. Various courses have been therefore concerned by an instructional design process, which enabled their transformation in an online version.

In this context, and since we were the instructional designers of many online courses, we have been able to study the constraints to be considered in transforming a course based on active pedagogy into an online version. We also examined the impact of information and communication technologies on active learning, which is referred in this paper as "active e-learning". Our experience has also enabled us to identify a mapping between the concepts, related to an instructional method, needed in active courses and those needed in active e-courses. A step forward after this mapping

Manuscript received July 9, 2013; revised September 10, 2013.

Lilia Cheniti Belcadhi is with PRINCE Research UNIT, ISITC H-Sousse, Sousse University and Virtual University of Tunis, Tunisia (e-mail: 1cheniti@yahoo.fr).

Sonia Ayachi Ghannouchi is with RIADI Research lab, ISG, Sousse University, Tunisia. consisted in proposing a comprehensive meta-model that can be used to design active e-learning courses. To validate the proposed meta-model and the mapping for the instructional design of active e-courses, we considered the KAB (Know About Business) case study. Indeed, this course has been designed by the ILO (International Labor Organization) and concerned an entrepreneurship education program for higher and vocational Education. The KAB course has been transformed into an online version. A learning management system (Moodle) has been used in order to provide collaboration and communication facilities, and to combine the positive effects of active learning and online learning. This active KAB e-course has been experimented in some Tunisian universities. In particular we have been interested in the training of trainers, which has been offered to 16 learners. In this context we developed and submitted a questionnaire to these learners and analyzed the answers given. Histograms have been generated to emphasize results of our analysis, which permitted us to validate the proposed meta-model.

The paper is structured as follows: First we introduce active learning and the benefits of its web-based version. We then provide an outline of our research questions, followed by a mapping exercise between the techniques used in face-to-face active courses and those used in online courses. In section five, we look at research conducted in this area and introduce our active e-learning meta-model, with a focus on the main functionalities needed in this type of learning. We then outline a case study which follows from the KAB experiment to validate the concepts presented in our model.

Finally a discussion is provided to highlight the main lessons and recommendations concerning the use of this model in the instructional design of active e-courses and its potential for generalization.

\section{ACTIVE LEARNING AND ICT}

Active Learning is defined as a planned series of actions or events to invite the participant to process, apply, interact and share experiences as part of the educational process. When active learning strategies are used, the participant is reading, talking, writing, describing, touching, interacting, listening and reflecting on information and materials presented [2].

Active learning promotes problem solving, critical thinking and manipulation of materials, analysis, synthesis and evaluation of information. Active learning focuses on the desired outcome for the participant as a result of the learning activity [2]. Several studies have shown that students prefer strategies promoting active learning to traditional lectures [3].

Much of the literature on active learning shows a 
significant improvement in long term retention and level of understanding. [4] .Furthermore, active learning improves student attitudes and develops thinking and writing skills, which is why it is recommended as a teaching method to improve learning [5].

In addition, the development of ICT have enabled the creation of tools which make collaborative work easier, such as communication tools (e-mail, forum, chat, videoconference, ...) and document sharing and management tools. Concerning courses based on ICTs, we can find in [6] a set of dimensions that has been identified needed to ensure quality in e-learning courses. Among these dimensions, we find interaction, course structure and learner support. These dimensions are also important aspects to consider in the instructional design of active e-courses. Indeed a major benefit of the use of active methodologies together with ICTs is that they contribute to the development of students' capacity to actively research and undertake responsibility for their own learning process, and to solve problems using their own resources.

\section{RESEARCH QUESTIONS}

Active learning aims to focus on the learner, on his/her needs and on his/her involvement in the learning process. Enhancing active learning with ICTs would enable learner to achieve better comprehension, retain the information for a longer period and find the course more stimulating and useful.

More precisely, in this work, we propose the following research questions, concerning the instructional design of active e-courses:

- How to transform an active course into an active e-course and which tools enable active learning in e-courses?

- Which concepts are taken into consideration during the instructional design of online courses, how are they classified and how are they linked?

- Which learner skills are targeted by active e-courses?

- Which tutor skills are required for tutoring an active e-course?

- What are the key benefits that can be expected from the design and use of an active e-course?

Table I visualizes the mapping between both techniques and various instructional methods. The presented instructional methods are detailed below [7], [8].

In the following section we propose a meta-model in which all the methods/techniques presented in table 1 and used to ensure active e-learning appear as concepts.

\section{Meta-Model FOR ACTIVE E-LEARNING}

\section{A. Related Work}

Many models exist in literature about the way in which the instructional design of online courses must be realized. Nevertheless, these models generally don't consider courses based on active pedagogy. In fact, Esseff and Esseff [9] developed their approach for instructional design and proposed the IDLS model composed of the following components: Design a task analysis; Develop criterion tests and performance measures, Develop interactive instructional materials and Validate the interactive instructional materials.

TABLE I: MAPPING BETWEEN ACTIVE LEARNING AND ACTIVE E-LEARNING

\begin{tabular}{|c|c|c|}
\hline $\begin{array}{l}\text { Instructional } \\
\text { Method }\end{array}$ & $\begin{array}{l}\text { Active Learning } \\
\text { Technique }\end{array}$ & Active E-lerning Technique \\
\hline Case methods & $\mid \begin{array}{l}\text { Paper case studies, } \\
\text { External } \\
\text { Interveners }\end{array}$ & $\begin{array}{l}\text { Online documents for case } \\
\text { studies ( Pdf, Word, ...) Audio, } \\
\text { video recording of case studies } \\
\text { video recording of external } \\
\text { interveners }\end{array}$ \\
\hline $\begin{array}{l}\text { Team Based } \\
\text { Learning }\end{array}$ & $\begin{array}{l}\text { Large Group } \\
\text { Discussions, } \\
\text { Small Working } \\
\text { Groups, } \\
\text { Small group } \\
\text { projects }\end{array}$ & $\begin{array}{l}\text { Discussions and working using } \\
\text { collaborative and } \\
\text { communication tools } \\
\text { Forums for Group discussion } \\
\text { Chat for group synchronous } \\
\text { communication } \\
\text { Wiki for group collaborative } \\
\text { work }\end{array}$ \\
\hline $\begin{array}{l}\text { Focused- } \\
\text { discussion }\end{array}$ & $\begin{array}{l}\text { Live Class } \\
\text { discussion } \\
\text { Live Group } \\
\text { discussion }\end{array}$ & $\begin{array}{l}\text { General Forum Discussions } \\
\text { Forums for Group discussion } \\
\text { Chat for group synchronous } \\
\text { discussion }\end{array}$ \\
\hline Role-Play & $\begin{array}{l}\text { Face-to-face } \\
\text { Role-play }\end{array}$ & $\begin{array}{l}\text { Online cooperative games } \\
\text { Online individual games }\end{array}$ \\
\hline Simulations & $\begin{array}{l}\text { Face-to-face } \\
\text { Serious Games }\end{array}$ & $\begin{array}{l}\text { Online cooperative games } \\
\text { Online individual games }\end{array}$ \\
\hline $\begin{array}{l}\text { Lecture \& } \\
\text { Direct } \\
\text { Instruction }\end{array}$ & $\begin{array}{l}\text { Presentation } \\
\text { Paper lecture } \\
\text { notes } \\
\text { Paper } \\
\text { documents }\end{array}$ & $\begin{array}{l}\text { Online learning resources (Pdf, } \\
\text { Word, ppt, ...) }\end{array}$ \\
\hline $\begin{array}{l}\text { Problem } \\
\text {-Based } \\
\text { Learning } \\
\text { (PBL) \& } \\
\text { Inquiry } \\
\text { Learning }\end{array}$ & $\begin{array}{l}\text { Brainstorming, } \\
\text { Collect of } \\
\text { Information } \\
\text { Paper surveys }\end{array}$ & $\begin{array}{l}\text { Discussion Forums, Chats } \\
\text { Mind mapping tools } \\
\text { Web search and collect of } \\
\text { information } \\
\text { Electronic surveys }\end{array}$ \\
\hline $\begin{array}{l}\text { Individual } \\
\text { Assessment }\end{array}$ & $\begin{array}{l}\text { Individual } \\
\text { assignments } \\
\text { Individual } \\
\text { presentation } \\
\text { Participation in } \\
\text { class } \\
\text { discussions }\end{array}$ & $\begin{array}{l}\text { Individual online assignment, } \\
\text { Quiz } \\
\text { Assessment of individual } \\
\text { contributions in } \\
\text { discussion forums }\end{array}$ \\
\hline $\begin{array}{l}\text { Group } \\
\text { Assessment }\end{array}$ & $\begin{array}{l}\text { Group } \\
\text { assignments } \\
\text { Face-to-face } \\
\text { peer } \\
\text { Assessment }\end{array}$ & $\begin{array}{l}\text { Group online assignments, } \\
\text { Group wiki } \\
\text { Online Peer Assessment } \\
\text { (Surveys, E-forms..) }\end{array}$ \\
\hline
\end{tabular}

We also find the Dick and Carey Systems Approach Model for Designing Instruction which includes interconnected sets of procedures and techniques employed by the instructional designer to design, develop, evaluate, and revise instruction [10]. Another model, which can be applied for various types of courses is the ADDIE model, which is a generic and a simplified instructional systems design (ISD) model. It is composed of the following phases: Analyze, Design, Develop, Implement, and Evaluate [11].

On the one hand, these models focus more on the steps to be followed in order to perform the instructional design of courses. They do not take into consideration the specificities of each pedagogical and communication technique necessary to these courses. Moreover these models do not focus on the use of ICTs in such courses. 
On the other hand, we observe that a lot of work has been done in the field of the instructional design rather than on hypermedia designing of courses. Most of the design methods that have been used are general purpose hypermedia design methods which do not allow conformance of design models to latest learning technology standards. In [12], an attempt for facilitating the conceptual design of web-based educational application by meta-modelling content and navigational structure of courses is given. We find also in [13] a pedagogical meta-model composed of four packages: the learning model, the unit of learning model, the domain model and the theories of learning and instruction. However in this model the focus is on the learner and not on the role of staff.

Models for active learning have been addressed in some research. For example, IMS has proposed a model for active learning based on its learning design specification [14]. However, the specificities of technological environments are not addressed in this model.

In [15] a learning model made up of three interdependent and mutually reinforcing components is developed that is based on current learning theory, practice and research. Moreover, in [16] the authors propose a model for self directed learning. Whittington and Yacci propose the Active Learning for Classroom Management Model as a method to structure active learning experiences [17].

All these models focus more on active pedagogy and consider neither the instructional design of these courses nor the role of ICTs in this type of courses.

\section{B. Meta-Model Description}

The mapping provided in section 4 , leads us to identify all instructional methods, means and techniques used to ensure active e-learning. Based on these concepts, we propose in this section a meta-model that constitutes a theoretical framework for describing active e-course, and permits us to answer some of our research questions outlined at the beginning of this work. The meta-model (Fig. 1) is divided into three sub-meta-models: instructional methods sub-meta-model, skills sub-meta-model and technological media sub-meta-model.

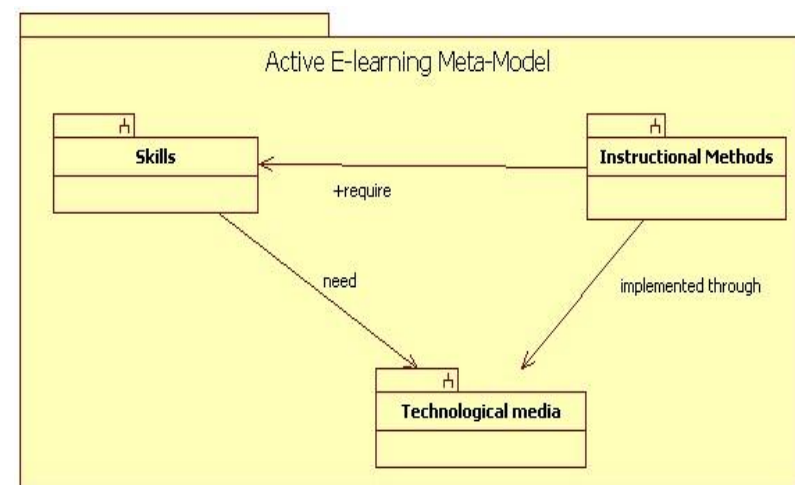

Fig. 1. General active e-learning meta-model.

These sub-meta-models outline pedagogical and technological concepts needed in active e-courses as well as targeted learners skills and required tutors skills for deploying such courses. The first sub-meta-model concerns the instructional methods and refers to the pedagogical concepts needed to deploy learning resources and activities in active e-courses. The second sub-meta-model addresses technological media and is related to tools, needed to ensure communication and collaboration among learners, and types of online resources offered for learners. The last sub-meta-model is about skills and involves concepts related to targeted learners competencies and required tutors competencies in active e-courses.

\section{1) Instructional method sub-meta-model}

The instructional methods detailed in our mapping are presented in this sub-meta-model and are in relationship with activities and resources required for delivery of active e-courses. This sub-meta-model addresses the pedagogical level needed in active courses. This level includes the concept of activity which is practiced by a learner. Activities may be either learning activities or may target knowledge evaluation of a learner or learners and are then considered as assessment activities. The content proposed to learners in active e-courses is composed of activities and learning resources, is related to a set of objectives and has specific ergonomics. The resources come in the form of lecture notes or case studies. We have considered this typology, because it is most appropriate to active learning. The various concepts are given in the following figure (Fig. 2).

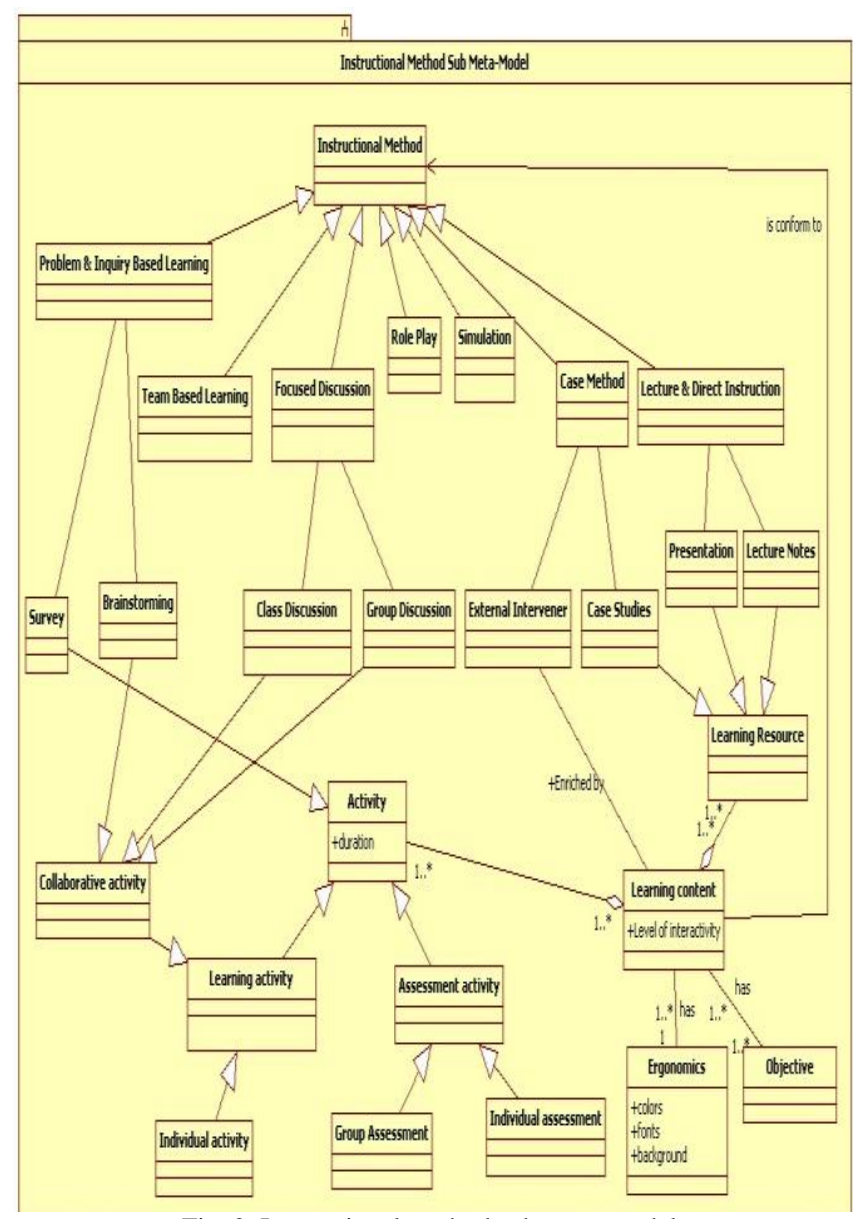

Fig. 2. Instructional method sub-meta-model.

\section{2) Skills sub-meta-model}

In this sub-meta-model, we consider the main skills required for the tutor and the targeted ones for learner in active e-courses. The learner may belong to a working group and has the possibility to practice the proposed activities and access a learning content. 
Learners are assisted by tutors who demonstrate some key competencies, including group facilitation and animation. In this type of course, learners will also acquire competencies of an intellectual, methodological, personal and social nature. Details regarding these different skills are presented in the following figure (Fig. 3).

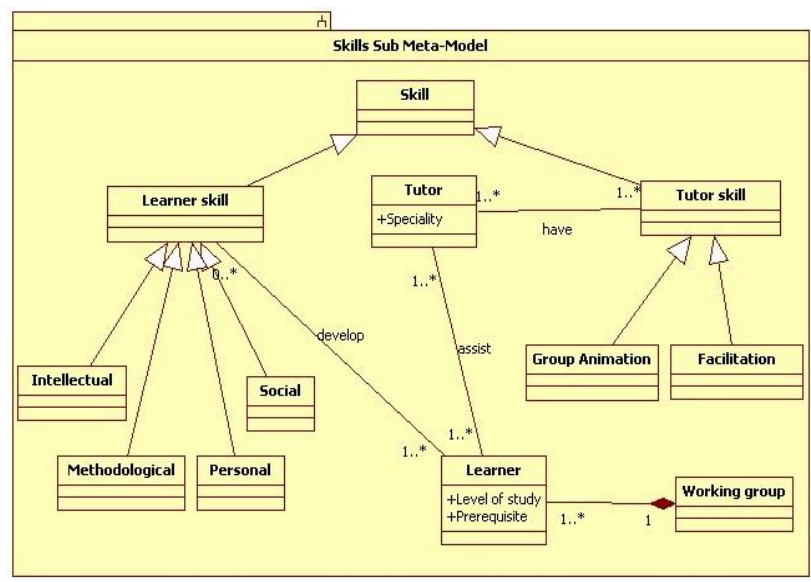

Fig. 3. Skills sub-meta-model.

\section{3) Technological media sub-meta-model}

To deploy an active e-course, we need to use various technological media including tools and online resources.

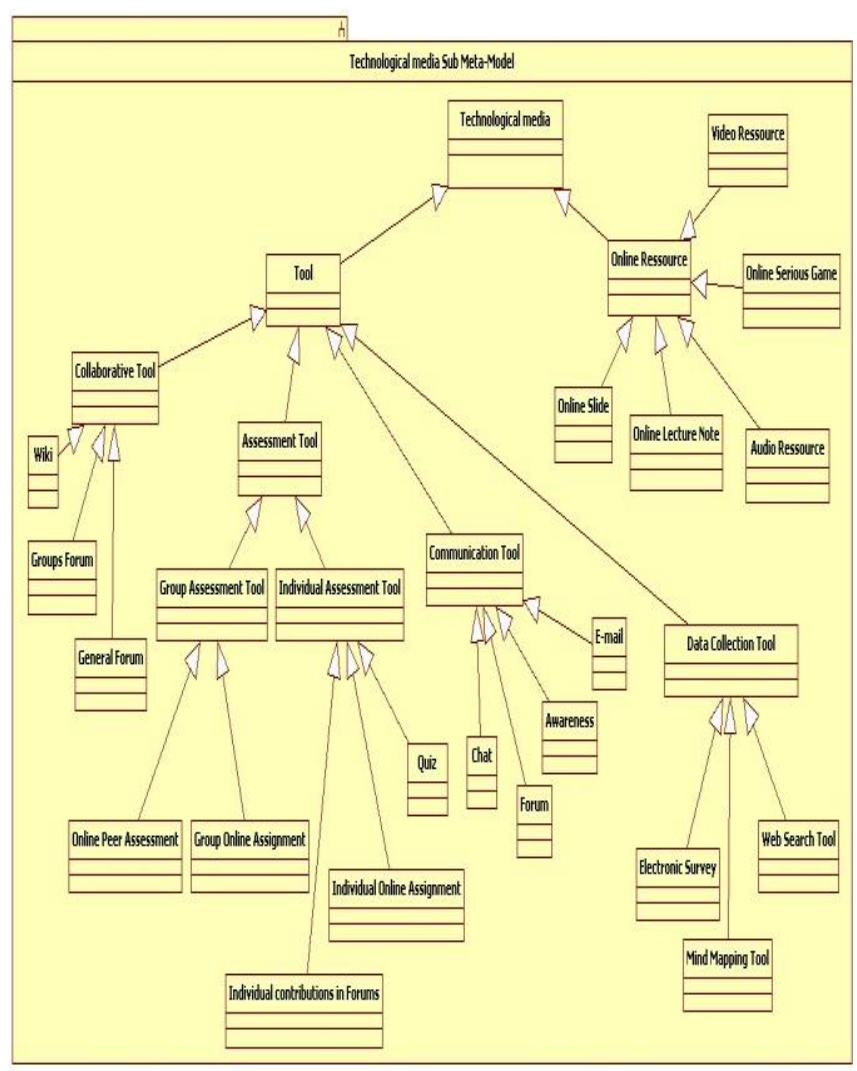

Fig. 4. Technological media sub-meta-model.

This technological sub-meta-model addresses four types of tools that should be adopted by learners in an active e-learning environment: communication tools, collaborative tools, assessment tools and data collection tools. The first type includes chat, forum, awareness and email. The second type includes wiki, general forum and group forum. The third includes individual and group assessment tools. The last type concerns data collection tools such as mind mapping tools, surveys and web search tools.

Concerning the online resources described in this technological sub-meta-model, various types are considered, including online lecture notes and slides, audio and video resources and online serious games. Details regarding these concepts are given in Fig. 4.

\section{CAse Study: KAB Active e-Course}

The KAB (Know About Business) course draws on the successful introduction of this program by ILO in more than 20 countries since 1996. It is in this context that collaboration started in January 2008 between the university of Sousse and ILO [18]. The project included three phases. The first phase consisted in transforming the content of the KAB program into an online version. A team composed of experts in e-learning was tasked with setting up the online version. This group was composed of experts from Algeria, Morocco and Tunisia. The work was supervised by the Swiss Group of Cooperation in e-learning (CoseLearn). The second phase consisted in launching the pilot teaching of this program in four Tunisian universities during two periods of six-months.

A group of 16 participants from these universities were trained on the content and the teaching approach and the active e-course was offered to approximately 1000 students. The third phase consisted in evaluating this pilot experiment and studying the possibilities to generalize the program to the Tunisian university system. The main KAB objectives are to positive attitudes towards enterprises and self-employment.

KAB content divided in nine modules was restructured and transformed during one year using ICT tools in order to make it more interactive and accessible online. The process produced a set of pedagogical web-based resources in various formats including Word documents, PowerPoint presentations, Scorm packages, Flash animations, etc.

These resources were deployed on the learning management system Moodle using communication and assessment tools. Once the modules were prepared, a pilot experiment was launched in four Tunisian universities, involving approximately 1000 students.

\section{Meta-Model VALIDATION}

In this section we describe the approach, that we adopted in order to validate the elaborated meta-model.

\section{A. Aim of Case Study and Participants}

In this case study, our aim was to give more insight in the possibilities of designing and deploying an active e-course through a Learning Management System (LMS). The pilot case study was conducted on KAB course offered by the University of Sousse. In this exploratory study, the number of participants was 21 , but those who concretely participated in the evaluation were 16 from 4 Tunisian Universities. Data was gathered at the end of the course from the participants.

\section{B. Research Methodology}

The research methodology can be divided into three parts. In the first part, we designed and elaborated a questionnaire 
that permitted us to validate the established meta-models. In the second part, we conducted training on KAB active e-course and distributed the questionnaire to learners, who participated in the course. In the third part, we collected information from learners and proceeded to their analysis to permit an evaluation of our case study and therefore a validation of our meta-model.

\section{Questionnaire: Design and Procedure}

Based on the active pedagogy and active e-pedagogy processes, we have developed a meta-model which draws upon several modeling concepts and constraints. The design of the questionnaire will help us validate this meta-model and facilitate its future uses in online courses based on active learning. This questionnaire, which can be found in appendix A, has been elaborated and distributed to learners. It concerned learner's attitude towards active e-course and consisted of Likert-scale type questions.

These questions were arranged in four thematic sections. The first section is composed of six questions. It highlights the concepts needed for the instructional design of this type of course and is related to both instructional methods sub-meta-model and technological media sub-meta-model. The second and the third sections concern the skills sub-meta-model. The second section is composed of eight questions related to learner competencies needed in active e-learning. These competencies can be divided into three types: intellectual skills, methodological skills and personal and social skills. The third section includes two questions to assess the skills required from the tutor in an active e-learning, particularly in relation to the management of group work and the facilitation of learning.

The fourth section includes four questions not directly related to our meta-model, but more generally to the efficiency and productivity of such active e-learning.

\section{Data Analysis and Results}

Given the exploratory nature of the study, and despite the limited sample size, the results of the questions presented in the questionnaire have been deeply analyzed. Responses to all Lickert-scale questions in the questionnaire and concise observations of learners were collated into a single document Raw data functioned as the essential unit of analysis. Given the context of our research, a data analysis has been conducted with respect to our questionnaire sections.

The first section assesses the scenario adopted for the online version of the KAB online course. The results of the evaluation have shown that ergonomics (colors, fonts, backgrounds), structure, level of interactivity, degree of variety, assessment activities and scheduling of activities are important aspects to consider in active e-learning courses.

Interactivity (i.e. hyperlinks, animations, etc.) also plays an important role in learning and should be further enhanced in active learning e-courses to enable the simulation of some activities

The questionnaire allowed us also to evaluate the learners' competencies that are presented in our meta-model for active e-learning and to estimate their importance. These competencies can be divided into three types: intellectual skills, methodological skills and personal and social skills.
Concerning the intellectual skills, our evaluation has shown that this kind of active e-learning enhances the critical thinking capacities of learners and gives them the opportunity to express their opinion and criticize the opinions of other participants. Regarding the methodological skills, we observe that active e-learning improves methodological know-how of learners by giving them the opportunity to plan and organize information and to layout content Tutor skills, also presented as core concepts in our meta-model, were evaluated on the basis of our questionnaire. The first skill relates to management of group work. The majority of learners strongly appreciate the tutor's role as a facilitator of group work. The second skill concerns the facilitation of learning. We observe that the majority of learners strongly appreciate the tutor's role as a facilitator and ot as a traditional teacher: instead of explaining concepts. He /she leads learners to discover and understand the course through practice activities. Section four is about appreciation of active e-learning by learners. First we observe that learners strongly appreciate the idea of using active e-learning and strongly agree that active-learning improves their performance, more precisely their knowledge assimilation and productivity.

\section{DISCUSSION}

In order to transform an active course into an active e-course, an instructional design process has to be adopted. This process of instructional design and active e-course development must be based on a mapping between the face-to-face version and the online version of each instructional method. This mapping is composed of concepts needed in traditional active learning and their equivalent concepts in the online version. It was used in the transformation process of our case study and was therefore validated. The questionnaire permitted us to validate the sub-meta-models presented previously. Indeed, section one permitted us to validate concepts presented in both instructional methods sub-meta-model and tools sub-meta-model. Sections two and three were used to validate

concepts related to skills sub-meta-model. Section four contributed to validate general acceptance of active e-courses.

These sub-meta-models constitute a theoretical framework for conducting the instructional design of active e-courses. We finally conclude that the results of our evaluation show that active e-learning was well received by learners, particularly in terms of improving performance, productivity and efficiency. This leads us to confirm the adequacy of e-learning with active based courses. In a previous work, we have analyzed and designed the various tutor functions needed in classical e-course [19]. These functions are still included in the required competencies for delivery of active e-course.

\section{CONCLUSION AND FUTURE WORK}

In this paper we proposed a meta-model of active 
e-learning concepts, which can be used as a reference to transfer an active course to an e-learning environment.

The KAB course has inspired us to analyze in depth the active e-learning approach and to evaluate the proposed meta-model. We conclude that an e-learning version of an active course could allow an equivalent degree of interactivity and even a higher degree of interactivity for some activities. This is made possible through the possibilities offered by the ICTs. Active e-courses are very stimulating as they play a critical role in developing learners' personal and social skills as well as their critical thinking and methodological abilities. Moreover, we have argued that this type of course strongly relies on tutor competencies in terms of group regulation and learning facilitation.

This evaluation shows that more efforts need to be deployed in the instructional design of active e-learning courses. Therefore, in our future work, we intend to propose an authoring tool that can be used by instructional designers in order to transform an active learning course in an e-learning mode. The proposed meta-model will be integrated into this authoring tool and serves as a reference for the instructional designers of active course. An alternative perspective could be to go deeper in each of the sub-meta-models and focus for example on some techniques used in active e-learning such as group work, group assessment, and project based learning.

\section{APPENDIX}

Appendix A: Evaluation questionnaire of the e-learning based on active learning related to the $\mathrm{KAB}$ course. . For each question, tick the adequate case $(\mathrm{X})$. Notations are from 1 (the lowest) to 5 (the highest).

\begin{tabular}{|l|l|l|l|l|l|}
\hline \multicolumn{1}{|l|}{} & $\mathbf{1}$ & $\mathbf{2}$ & $\mathbf{3}$ & $\mathbf{4}$ & $\mathbf{5}$ \\
\hline $\begin{array}{l}\text { I. Questions on the scenario adopted for } \\
\text { the course online CLE }\end{array}$ & & & & & \\
\hline $\begin{array}{l}\text { 1. I appreciate the ergonomics of the } \\
\text { presented course (colors, fonts, } \\
\text { backgrounds ...) }\end{array}$ & & & & & \\
\hline $\begin{array}{l}\text { 2. I find that the structuring of the course } \\
\text { (resources and activities) is good. }\end{array}$ & & & & & \\
\hline $\begin{array}{l}\text { 3. I find that the level of interactivity of the } \\
\text { course (hyperlinks, animations ...) is } \\
\text { correct. }\end{array}$ & & & & & \\
\hline $\begin{array}{l}\text { 4. I had opportunity to perform individual } \\
\text { activities and collaborative activities. }\end{array}$ & & & & & \\
\hline $\begin{array}{l}\text { 5. I find the assessment activities } \\
\text { (assignments, MCQ, projects ...) well } \\
\text { chosen. }\end{array}$ & & & & & \\
\hline $\begin{array}{l}\text { 6. I find that the distribution of time } \\
\text { depending on the nature of the course is } \\
\text { satisfactory. }\end{array}$ & & & & & \\
\hline $\begin{array}{l}\text { II. Questions on competencies covered } \\
\text { by the active learning }\end{array}$ & & & & & \\
\hline $\begin{array}{l}\text { 7. I expressed my opinion and criticized } \\
\text { the opinions of other participants. }\end{array}$ & & & & & \\
\hline $\begin{array}{l}\text { 8. I was able to take advantage of the } \\
\text { information in the various resources of the } \\
\text { course. }\end{array}$ & & & & & \\
\hline $\begin{array}{l}\text { 9. I had the opportunity to establish a plan } \\
\text { through the development of a document or } \\
\text { a project. }\end{array}$ & & & & & \\
\hline $\begin{array}{l}\text { 10. I had the opportunity to structure and } \\
\text { format a range of information through the } \\
\text { development of a document or a project. }\end{array}$ & & & & & \\
\hline $\begin{array}{l}\text { 11. I managed to interact with colleagues } \\
\text { and tutors, using available communication } \\
\text { tools, such as chat and forum. }\end{array}$ & & & & & \\
\hline 12. The distribution of tasks between the & & & & & \\
\hline
\end{tabular}

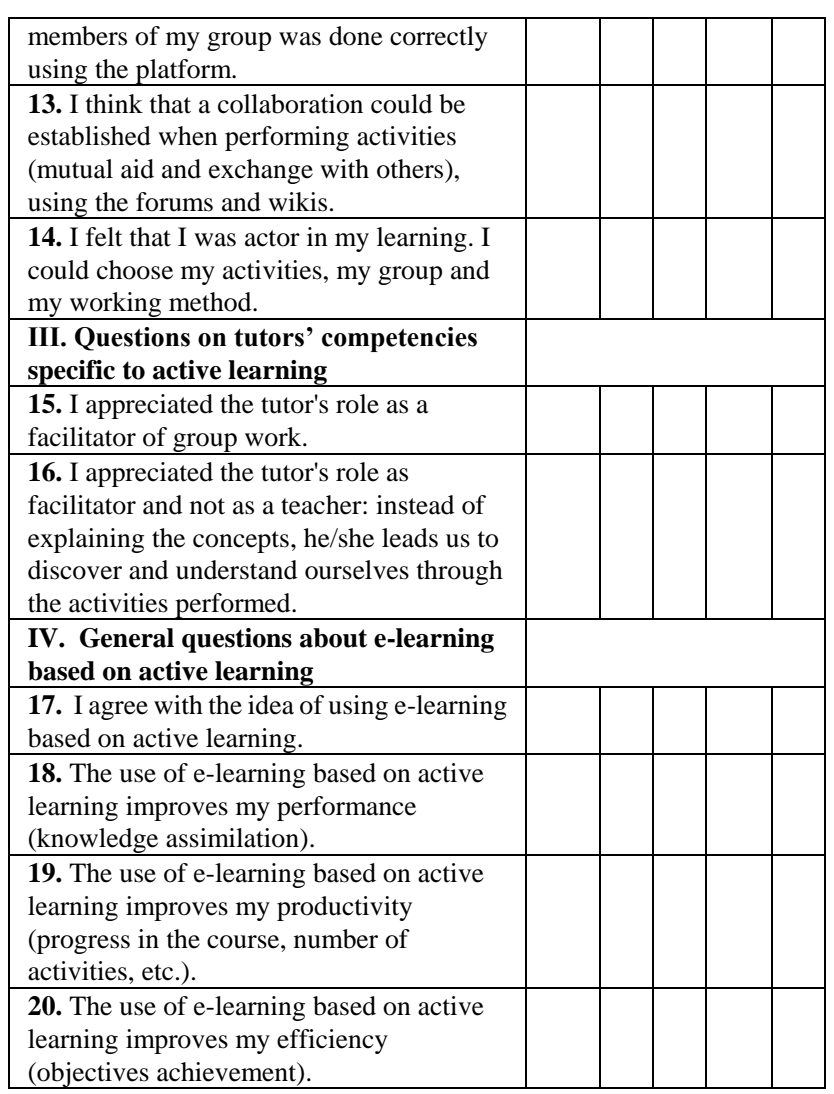

\section{REFERENCES}

[1] A. Glasgow, Doing Science Innovative Curriculum for the Life Sciences, UK: Corwin press, 1996

[2] Ineedce. (2012). [Online]. Available: http://www.ineedce.com/userfiles/4/pdf/CEStrategiesPpt.pdf,

[3] NTLF. (2012). [Online]. Available: http://www.ntlf.com/html/lib/bib/91-9dig.htm

[4] T. Metcalf, "Listening to your clients," Life Association News, vol. 92, no. 7, pp. 16-18, 1997.

[5] L. M. Regueras et al., "Effects of Competitive E-Learning Tools on Higher Education Students: A Case Study," IEEE Transaction on Education, pp. 279-285, vol. 52, no. 2, 2009.

[6] J. Insung, "The dimensions of e-learning quality: from the learner's perspective," Educational Technology Research and Development, vol. 59, no. 4, pp. 445-464, 2010.

[7] Alliance for clinical education. (2012). [Online]. Available: http://familymed.uthscsa.edu/ACE/chapter5.htm

[8] Office of Information Technology, OIT. (2012). [Online]. Available: http://itc.utk.edu/ bobannon/in_strategies.html

[9] P. J. Esseff and M. S. Esseff, Instructional Development Learning System (IDLS), 8th ed., ESF Press, pp. 1-12, 1998.

[10] W. Dick, C. Lou, and O. C. James, The Systematic Design of Instruction, 6th ed., Allyn \& Bacon, pp. 1-12, 2005.

[11] A. W. Strickland (2006). ADDIE. Idaho State University College of Education, Science, Math \& Technology Education. [Online]. Available: http://ed.isu.edu/addie/index.html

[12] S. Retalis, A. Papasalourus, and M. Skordalakis, "Towards a generic conceptual design metamodel for web-based educational applications," presented at the conference Second international Workshop on Web oriented software technology IWWOST'02, Spain, June 2002.

[13] R. Koper and R. V. Es, "Modeling units of learning from a pedagogical perspective," R. McGreal, (Ed.), Online education using learning objects (open and flexible learning), RoutledgeFalmer, Canada, 2004.

[14] IMS. (2011). MS Learning Design Information Model, Version 1.0 Final Specification [Online]. Available: www.imsglobal.org/learningdesign/ldv1p0/imsld_infov1p0.html

[15] E. L. Haslam, "A learning model that develops students' active learning and reflective practices," presented at the Frontiers in Education Conference, on 27th Annual Conference. Teaching and Learning in An Era of Change, Washington, DC, November 05 - 08, 1997.

[16] L. Song and J. R. Hill, "A Conceptual Model for Understanding Self-Directed Learning in Online Environment," Journal of Interactive Online Learning, vol. 6, no. 1, 2007. 
[17] K. Whittington and M. Yacci, "Active Learning for Classroom Management Model," presented at the Informing Science \& IT Education Conference (InSITE), Bulgaria, June 22 - 25, 2008.

[18] ILO. International Labor Organization. What is KAB? [Online]. Available: http://kab.itcilo.org/en/what-is-kab

[19] R. Lewis et al., "Analysis and Modeling of Tutors functions," Computer Applications in Engineering Education (CAEE), Wiley Editions, 2010, DOI: 10.1002/cae.20511.

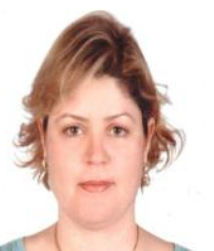

Lilia Cheniti Belcadhi is an assistant professor of Computer Science at the University of Sousse, Tunisia, and a graduate of the University of Braunschweig in Germany where she read for a master's degree in Computer Sciences. She is a member of the PRINCE Research group at the University of Sousse and her $\mathrm{PhD}$ was realized in collaboration with the Semantic Web group at the Institute of Information Systems of the University of Hannover in Germany. Her research interests include innovative learning methods, technology enhanced learning, Semantic Web, Web-based assessment and e-learning.
She is involved, as part of her ongoing research, in several e-learning projects and has co-authored various online courses for graduate students. She is currently head of online earning department at her University

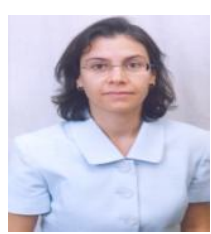

Sonia Ayachi Ghannouchi has a diploma in computer sciences engineering obtained in 1993. Her PHD, presented in 1999, was entitled "a generic approach for data reverse engineering". She's an assistant professor in computer sciences at the High Institute of Management of Sousse, in the University of Sousse. Her taught courses include: "Databases," "Information systems" and "Software Engineering" offered in her University and "Reengineering" offered in the University of Manouba. Her research interests include: Business Process Reengineering, Software Reengineering and e-learning. She is involved in several e-learning projects and has co-authored and tutored various online courses for undergraduate and also graduate students. 